\title{
Youth Participation in Community Evaluation Research
}

\author{
BARRY CHECKOWAY AND KATIE RICHARDS-SCHUSTER
}

\begin{abstract}
Should young people participate in community evaluation research and, if so, what roles should they play? We believe that youth participation is desirable, but that it remains relatively undeveloped as a field of practice or subject of study. For this reason, this paper provides perspective on the increasing involvement by young people, identifies the participation patterns and evaluation roles of young people, and draws conclusions from empirically-based practice. It draws on the available literature, including our own participatory evaluation of a project intended to increase youth participation in organizational development and community change.
\end{abstract}

\section{SHOULD YOUNG PEOPLE PARTICIPATE IN COMMUNITY EVALUATION RESEARCH AND, IF SO, WHAT ROLES SHOULD THEY PLAY?}

Young people already participate in community evaluation research. In our experience, for example, they document the dangers of toxic wastes near their schools and present the findings to health officials; conduct a citywide survey of racial attitudes in the schools and create an anti-racism program for middle schoolers; evaluate programs in the community center and make recommendations to the board of directors; respond to proposed cuts in youth services by conducting focus groups and petitioning the city council; and document the criminalization of youth in the newspaper and present the findings to the editors (Figueroa et al., 2000).

Young people participate in community evaluation research, but their participation is uneven. Some young people participate with fervor, and others express interest but are unsure how to proceed, and others try to proceed but lack support from adults or face obstacles in the community. It is difficult to assess the overall scope or quality of participation, however, for despite its incidence and potential as a field of practice, youth participation remains undeveloped as a subject of study.

Barry Checkoway - Professor of Social Work and Urban Planning, National Evaluation Director, Lifting New Voices, University of Michigan, Ann Arbor, MI 48109, USA; Tel: (1) 734-763-5960; E-mail: barrych@umich.edu.

American Journal of Evaluation, Vol. 24, No. 1, 2003, pp. 21-33.

All rights of reproduction in any form reserved. ISSN: 1098-2140

(C) 2002 by American Evaluation Association. Published by Elsevier Science Inc. All rights reserved. 
We make the case that youth participation in community evaluation research is desirable, and that there is need for more knowledge of this approach. This paper draws on our review of the limited available literature, including our own evaluation of a national community-based youth participation project, in the hope that this will contribute to the scope and quality of work in the field. We provide a rationale for youth participation, a typology of evaluation roles for youth and adults, an illustrative example, and some questions for future work.

\section{PERSPECTIVES ON YOUTH PARTICIPATION}

Youth participation in evaluation research is a process of involving young people in knowledge development at the community level. It includes efforts by adults to involve young people in the research of public agencies and private institutions; work done by young people to organize their own research projects, with or without adult assistance; and efforts by youth and adults to work together in intergenerational partnerships. Youth participation refers to their active participation and real influence in the decisions that affect their lives, not to their token or passive presence in adult agencies. In this approach, participation quality is measured not only by its scope, such as the number of young people who attend a number of activities, but also by its quality. Participation quality is effective when people have some effect on the process, influence a particular decision, or produce a favorable outcome (Checkoway, 1998).

Youth participation in community evaluation research is an approach in which young people are active participants in the stages of knowledge development, including defining the problem, gathering the information, and using the results. When young people define their own problems rather than discuss the ones given by adult authorities; when they design their own age-appropriate methods rather than uncritically accept adult ones; and when they develop knowledge for their own social action and community change rather than "knowledge for its own sake" - when they work in these ways, as Wang and Burris (1997) contend, it can raise their consciousness and their spirit and move them to action.

Youth participation in community evaluation research can be viewed as a stage in the evolution of several related fields. These fields, and their stages of evolution, include "youth development," as it moves from a focus on problem prevention to one on community change promotion; "community participation," shifting in emphasis from the general community to particular class, race, and gender population groups (Sandercock, 1998); and "civic engagement" shifting from an awareness of youth disengagement to strategies for reengaging them (Putnam, 2000). Within "program evaluation," youth participation can be viewed as part of the movement from positivist to illuminative (Parlett \& Hamilton, 1976), responsive (Schwandt, 2001a, 2001b; Stake, 1975), utilization-focused (Patton, 1997), empowerment (Fetterman, Kaftarian, \& Wandersman, 1996), deliberative democratic (Greene, 2000; House \& Howe, 2000), and dialogical (Schwandt, 2001a) models. It also can be viewed as part of the movement of "social research" from action (Greenwood \& Levin, 1998) to participatory (Ansley \& Gaventa, 1997) to community based (Israel, Schulz, Parker, \& Becker, 1998) methodologies.

Viewing youth participation in context of other fields of practice and bodies of literature can be helpful to scholars, although such contextualization will likely interest adult professionals more than youth participants. It should be emphasized, however, that youth participation represents more than merely increasing the involvement of yet another community group. Indeed, because it represents the involvement of a traditionally excluded group whose 
participation is not familiar to most adults, it has the potential to challenge evaluation research in a more fundamental way.

We believe youth participation in community evaluation research is desirable for various reasons. First, it can be a legitimate way to develop knowledge for social action. Like other groups, young people want to take action and improve communities, and evaluation research can provide a source of credible information for action-taking. Similarly, community agencies want the best available information for making decisions, and young people have important perspectives for their consideration, especially in the evaluation of programs that serve them (Zimmerman \& Erbstein, 1999). The notion of setting a few more seats at the evaluation table for young people is consistent with professional practice principles in participatory community-based research (Nyden, Figert, Shibley, \& Burrows, 1997).

Second, youth participation in community evaluation research can enable young people to exercise their political rights. The United Nations Convention on the Rights of the Child protects the rights of young people to obtain information, express their own views, meet with others, and form associations. This, the most ratified rights statement in history, ensures the accessibility of young people to information and materials from diverse sources, and to freely disseminate information of social and cultural benefit. When youth participation is framed as a political right, it elevates the rationale for participation to another level of discourse (Fountain, 1995; Rajani, 2000).

Third, youth participation can allow young people to share in the democratization of knowledge. In an age when technical, expert knowledge predominates over knowledge derived from everyday experience and active citizenship, there is need for new strategies by which traditionally under-represented groups can mobilize knowledge resources as part of the broader movement for democratization. The "democratization of knowledge" has potential to break the monopoly on knowledge development and enable youth to have some of the information they require for competent citizenship (Ansley \& Gaventa, 1997; Gaventa, 1993; Moses, 2001). Because of our commitment to youth involvement in the "democratization of knowledge," we use the term "evaluation research" throughout this paper in order to broaden the basis for their involvement in both "evaluation" and "research" activities, with the hope that this construction may enable both evaluators and researchers to consider the possibilities.

Fourth, youth participation in community evaluation research can prepare young people for active participation in a democratic society. At a time when too many youth neither participate nor aspire to participation, there is need for new strategies of civic engagement which will awaken them to community conditions, enable them to reflect upon the root causes of problems, and motivate them to take action in a civil society. When research is viewed as participation, it contributes to "education for democracy" in accordance with the principles of John Dewey and other educational reformers.

Fifth, youth participation can strengthen the social development of young people in various ways, by increasing their individual involvement, their organizational development, and their ability to create community change. There has been no systematic study of the effects of youth participation at these multiple levels, but there is reason to expect subsequent studies will substantiate its effects on such measures as personal confidence, social connectedness, group decision-making, resource allocation, public awareness, and community outcomes (Checkoway \& Richards-Schuster, 2001a; Youniss \& Yates, 1997).

Based on our work to date, we conclude that youth participation in community evaluation has positive benefits. However, we also acknowledge that these benefits are not established by long-term study, and expect that subsequent studies will also identify the negative consequences 
of participation. For example, we expect that studies will document situations in which young people become frustrated when their roles as researchers are not taken seriously, or their findings are unheeded by adults, or when they are heeded but their utilization takes longer than they hoped. It would be unfortunate if young people began with high hopes, experienced obstacles, became disillusioned, and withdrew from participation, but this is normal with their adult counterparts. Such negative consequences of participation might be reduced by preparing young people and their adult allies more effectively for their roles in the process, but education and training are only one approach.

\section{EVALUATION ROLES OF YOUNG PEOPLE}

Young people already participate in community evaluation research in various ways. We have reviewed the limited literature, drawn upon our own research and practice, and identified the following participation patterns and evaluation roles of young people, as summarized in Table 1.

\section{Youth as Subjects}

Young people are often the subjects of research. In this pattern, adults conceive the research, gather the data, and develop knowledge in order to solve youths' problems, serve their needs, or improve their quality of life. In their roles as subjects, young people are observed, tested, measured, enumerated, and analyzed by the researchers. They are usually unaware of how the research was conceived, the information was gathered, or the findings were disseminated, even when they are described in its subsequent publications and benefit from the results.

For example, a university-based adult researcher was concerned about youth violence and decided to study how young people understood the violent neighborhoods in which they lived. He devised new neighborhood maps; involved young people in the identification of violent sites; asked them to discuss photographs of abandoned homes and neglected streets; and assessed their responses to name calling, lying and hitting, shooting and killing, and other violent behaviors, all in hope of creating new knowledge for violence prevention. He published papers in scholarly journals, presented findings to professional audiences, and won a prestigious award for his scholarly contributions.

In some studies, the number of subjects is large. For example, there are researchers who study thousands of young crime perpetrators, drugs users, school dropouts, and pregnant teenagers. There are longitudinal studies of young victims of adult neglect, poverty, racism, or other forces which affect young people. There are reports of interviews, focus groups, and social surveys of youth beliefs and behaviors, of the causes and consequences of social pathologies, and of the effects of education, health, and other human services which serve their needs. Survey research on young people as subjects is a big business, and government agencies and research institutions have established review procedures to protect the rights of youth as subjects.

Because adults often view young people as victims or problems who require proactive or ameliorative services, rather than as competent citizens capable of meaningful participation in society, it is not surprising that their evaluation research also emphasizes troubled youths and casts them as human subjects. Finn (2001) analyzes the representation of young people in this 


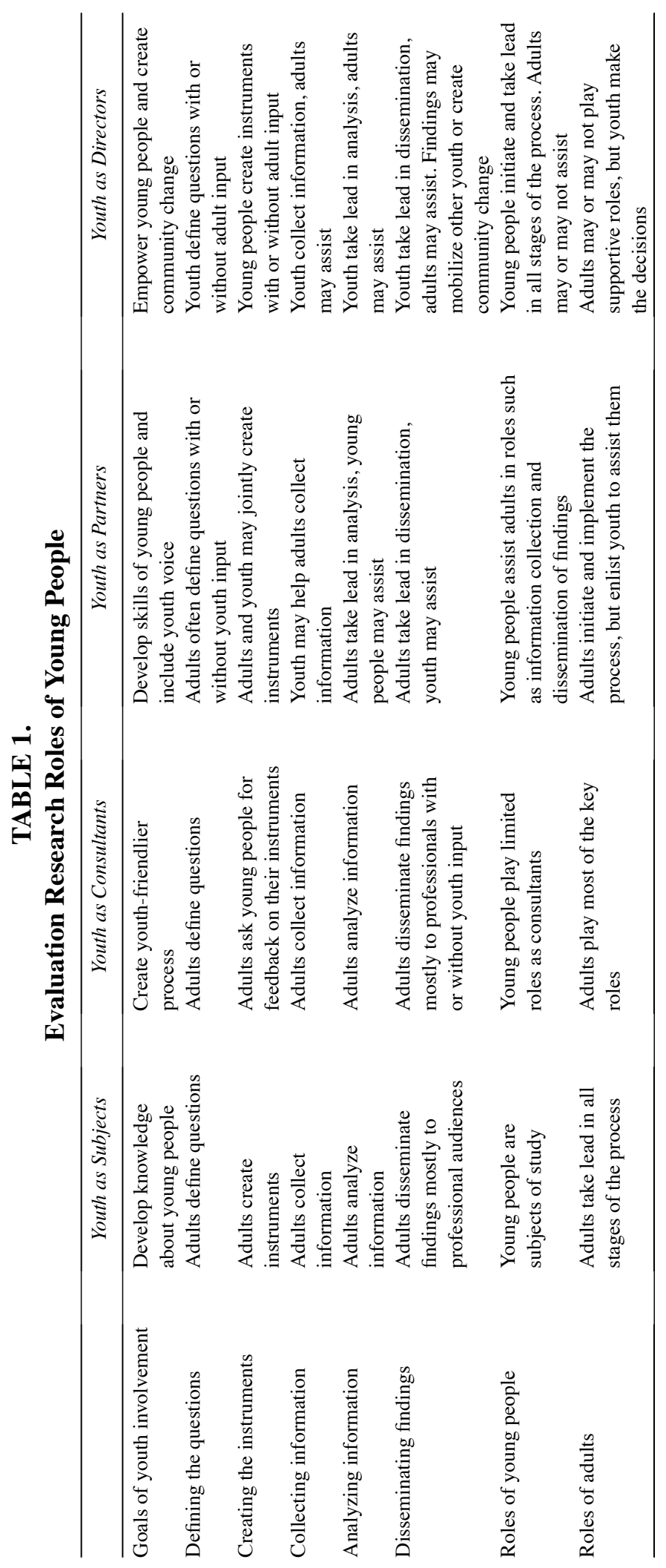


way, and documents its roots in the evolution of human services and the political economy of which they are part.

So strongly do some adult researchers care about such research that they apply it to teaching and training and advocate its utilization in services for youth. Some of the greatest advances in curative care derive from research conducted by adults who care about youths' well-being and respect their rights as subjects without involving them in the research process. Indeed, adult researchers might argue that increasing youth participation in research might even lessen its quality by involving them in technical decisions for which they are not qualified, an argument which might lead to broader discussion of the roles of laypersons in scientific research.

\section{Youth as Consultants}

Some young people play roles as research consultants. In this pattern, adults initiate a research project and consult with young people to make its operations more effective, such as when they advise on the age-appropriateness of interview questions or on the right places or times to interview respondents. Young people are recognized for their special knowledge about themselves as a group at a particular stage of human development, and adults may or may not use this information in their research decisions. When they do, it may represent their effort to make their evaluation more responsive to culturally-competent or age-appropriate factors which are easy for majority groups to ignore.

As consultants, young people may review the wording of interview questions, recruit respondents, participate in user-friendly focus groups, and occasionally comment on drafts of research reports. For example, University of Wisconsin researchers brought together youth and adults for focus groups discussions about their participation in decision-making. According to the researchers, "these focus groups gave us a chance to explore study issues by letting participants respond to one another in a structured format" (Zeldin, McDaniel, Topitzes, \& Calvert, 2000, p. 14). In another study, Ferguson (2000, p. 15) asked a young person to consult in her research. "He helped me put together the topic for my interviews with the other boys," she reports. "He saw patterns, relationships, contradictions, and disjunctures. He helped me decide-I might say he insisted - on the themes for the interviews I later conducted with the other boys."

\section{Youth as Partners}

Young people sometimes participate as partners in evaluation research. In this pattern, adults initiate a project and enlist youth as partners in intergenerational relationships which may be equal or unequal in their level of participation.

There are adult-youth research partnerships in the schools. In Utah, teachers partnered with students to study contaminated water near the school and to inform residents of danger. This adult-youth partnership helped convince public officials to clear up the site (Lewis, 1998). In Alaska, teachers partnered with students to collect data on an erosion problem, make a videotape of their findings, and present their recommendations to public officials in their community (Lesko, 1992). Campbell, Edgar, and Halsted (1994) describes the "student evaluator model" in which teachers select students for training, help them to formulate questions and collect information, guide them in report preparation, and support them throughout the process. 
There are youth-adult evaluation research partnerships at the community level. In Milwaukee, adult evaluators trained young people in evaluation methods, helped them to design their own approach, and enabled them to survey their peers about their opinions of local nonprofit youth serving agencies (Guidinger \& Linnane, 1996). In Savannah, adult evaluators wanted to amplify the voices of young people and hired middle-schoolers to survey classmates about the performance of a school-based family center (Metis Associates Inc., 1996). In San Francisco, adults and young people evaluated an after-school community center. Adults evaluated the adult programs, adult advisers facilitated the young peoples' evaluation of the youth programs, and the final report caused the center to make its programs more responsive to youth (Zimmerman \& Erbstein, 1999).

There are also partnerships with universities. For example, university-based researchers concerned with youth violence sought to help public health professionals better understand young peoples' perceptions of violence in their daily lives. They asked young people to collaborate in a street survey, prepared them to conduct interviews and gather information from youth respondents, and published a paper in a scholarly journal (Freudenberg, Roberts, Richie, \& Taylor, 1999). Also, McIntyre (2000) conducted a participatory research project with middle-school students in an urban community. She put cameras in the students' hands, collaborated with them in a photovoice project, and assessed conditions in the community. As a result of their research, the students organized a community-wide clean-up, prepared recommendations for presentation to local and state representatives, and rallied the community around their findings.

Adult-youth partnerships go beyond consultation to provide a greater measure of intergenerational involvement in which parties may be equal or unequal in their levels of participation. If both parties share interpersonal and institutional power, they take a step toward quality participation. If the power remains largely in adult hands, however, they do not (Arnstein, 1969; Hart, 1997).

\section{Youth as Directors}

Young people may organize their own research project, study problems of their own choosing, and work for solutions at the community level. Whether the project originates in reaction to a crisis or in a proactive desire to address an important issue, the process is rooted in their desire to take action rather than to develop knowledge for its own sake.

In New York, for example, young people decided to study the images of youth in the New York Times. They received training in research methods, media accountability, and public speaking; analyzed three months of newspaper coverage; and published their findings in an attractive report. They prepared fact sheets, conducted media workshops, and presented the information with recommendations to the editors (Figueroa et al., 2000).

In San Francisco, young people evaluated the municipal youth services provided in youth centers. With funding from a local foundation, they made site visits, conducted interviews and surveys, analyzed their findings, and prepared a report of their findings. They also provided recommendations to the mayor, community centers, and local funders (Y-MAC, 1997).

In Ann Arbor, Michigan, a group of teenagers became concerned about discrimination in the schools. They organized a group and conducted their own citywide survey of racial attitudes in the schools. Based upon this, they formulated an action plan and built community support for a program in which high schoolers educate themselves and younger children about discrimination. Today they have an activist core of young people who recruit members and train 
teenage facilitators for education work with thousands of children citywide (Winn, Morado, \& West, 1992).

Some youth groups make research a regular feature of their work. In New Mexico, for example, young people conduct ongoing research on youth-related policies and present their findings to community forums involving youth and adults. In California, young people conduct annual surveys of thousands of youth which help establish their priorities. Annual assessments, surveys, and summits have been regularized in many communities nationwide (Mullahey, Susskind, \& Checkoway, 1999).

"Youth as research director" is a role about which little is known. Our observation is that it places emphasis on action-taking rather than creating knowledge for its own sake, and on real-world issues rather than an academic exercise. Youth-directed research may be conducted with or without adult assistance, and adults who participate play supportive rather than directive roles in the process, although "adults as allies" is another role about which little is known (McLaughlin, Irby, \& Langman, 1994).

\section{LIFTING NEW VOICES}

Lifting New Voices (LNV) is an example of youth participation in community evaluation research. LNV is a demonstration project designed to increase the participation of young people 15-21 years old in organizational development and the creation of community change. Coordinated by the Center for Community Change with funding from the W. K. Kellogg Foundation and Ford Foundation, LNV aims to demonstrate what happens when youth and adults build the capacity of community-based organizations by increasing the involvement of young people (Checkoway \& Richards-Schuster, 2001a, 2001b).

Six community-based organizations in low-income areas were selected for participation in the project. Each organization has formulated a plan, formed a steering committee, hired a youth organizer, and established a structure for implementation. Each organization has opportunities for training and technical assistance, cross-site meetings, and national networking designed to support its involvement.

LNV is evaluated by a participatory community-based process which involves youth and adults in documenting their activities, assessing their experiences, and using their learning for improving their effectiveness. Each organization has a community-based evaluator who works with an evaluation committee of youth and adults to facilitate the process. Each evaluator prepares regular reports of their efforts, and the national evaluators analyze the activities across all sites and assess the project in terms of its overall objectives (Checkoway \& Richards-Schuster, 1999).

For example, People United for a Better Oakland (PUEBLO) has a community-based evaluator who herself is a young person, and a youth-adult evaluation team which meets regularly and evaluates their work. Team members use observations, interviews, surveys, video documentation, and other methods of data collection. They keep written reflection journals, discuss organizing campaigns and organizational activities, and report recommendations to the general membership. In a process evaluation of a campaign against a charter school proposal, for example, the team recognized the need for more adult involvement and recommended increased adult recruitment. Their recommendation led to more adult involvement in the campaign, which helped rally parents and other voters against the school board proposal which eventually led to the proposal's defeat. 
PUEBLO youth engage in various research activities. In response to reports of increasing rates of school suspensions and expulsions, PUEBLO young people organized a multiracial group of students, investigated public records, and conducted surveys in schools and communities. They concluded that the public schools used suspensions too often, that they compromised student learning and criminalized male students of color, and that they violated the due process rights of students. They prepared a report, developed a videotape, educated their peers about students rights, and recommended specific steps for action (Alvarado-Mena et al., 1999).

Also, Southwest Organizing Project (SWOP) has a youth-adult committee that meets regularly to evaluate their campaigns. Members use interviews, surveys, video documentation, and other methods of evaluation. They consult with youth and adults about priority issues, develop formal feedback processes, and enable the organization to become more responsive to the concerns of its members.

Young people at SWOP regularly use research in their organizing work. For example, as part of an effort to end racial discrimination of youth of color in a local mall, the SWOP youth conducted a survey about spending habits by youth, printed "brown dollars" representing the revenue of youth of color, distributed the dollars to the merchants, and mobilized a mass demonstration. Their actions sparked a lawsuit to protect their right to freedom of speech in shopping malls.

Although LNV's evaluation is ongoing, some preliminary observations are possible. First, youth and adults willingly participate in evaluation. In areas which have been economicallydisinvested and whose residents lack professional experience, community-based evaluators form youth-adult evaluation committees and employ a range of evaluation methods. Youth and adults formulate their own questions, gather their own information, and utilize the learning for improving their effectiveness. They create their own surveys and evaluation instruments, facilitate their own focus groups, conduct their own interviews, and hold regular meetings for reflection and assessment. Their active participation contrasts with images of them and their communities as unable to undertake work of this type.

Second, evaluation has effects on its primary participants. Young people come together, discuss common concerns, participate in decisions, and implement action plans. Adults help bring them together, provide encouragement and resources for activities, rally other adults to the cause, and address the obstacles they face in their negotiations with adult systems. Our preliminary observation is that the evaluation process has psychosocial impacts on both youth and adults, in addition to its organizational and community effects. According to the community-based evaluators, participation in evaluation research has helped in strengthen the critical thinking, research, public speaking, writing, and planning skills of both the youth and adults. In addition, both youth and adults have become more conscious of the role of evaluation and research in planning and organizing.

Third, evaluation is facilitated by the presence of an evaluator whose role is instrumental to this function, by adults who work well with youth, by young people who play leadership roles, and by resource organizations and national networks outside the community. Despite the obstacles to successful youth participation such as adultism, there are identifiable factors that facilitate these efforts, and we believe that these factors are becoming known.

Finally, youth and adults use evaluation as a tool for social action. Young people usually start with a real-world problem, employ methods to gather sufficient information, and aim to so something with what they learn. Their work begins with action in mind, they fit their methods to available resources, and the measure of their findings is in their utilization. For example, PUEBLO uses evaluation to strengthen their campaign strategy, SWOP uses 
evaluation research as an organizing tactic, and other LNV groups use evaluation research to identity issues of community concern. This contrasts with those adult evaluation researchers who want to contribute to the knowledge and who distinguish its dissemination and utilization from its development.

\section{OPPORTUNITIES AND OBSTACLES}

Young people participate in community evaluation research, but this work remains relatively undeveloped as a field of practice and subject of study. It is difficult to make broad generalizations from the limited available literature, but preliminary observations are possible.

There has been no comprehensive research on the effects of youth participation in community evaluation research, but we observe that participation can have psychosocial benefits for young people. In contrast to young people who are alienated or withdrawn from the community, participation promotes their personal and social development, including their sense of efficacy, their interpersonal competencies, their social connectedness with other youth and adults.

Youth participation in community evaluation research can contribute to the organizational development of young people. In contrast to young people who do not view themselves as a group that can come together on their own behalf, these initiatives involve them in identifying issues, collecting and analyzing information, and taking actions based on the findings. These initiatives enable young people to decide what they want to accomplish, organize a supportive structure, agree upon roles and responsibilities, and work together for a common cause.

Youth participation also can contribute to community change. At first young people are isolated and unorganized; then they come together to share concerns for a common cause; then they gather information and raise consciousness; and then they organize to address issues and become an entity of substance of power. When young people use research as participation, they can operate in indigenous initiatives or formal agencies; in education, health, or other human services; with diverse income, racial, and ethnic groups; and in rural and urban communities in industrial countries and developing areas (Johnson, Ivan-Smith, Gordon, Pridmore, \& Scott, 1998).

There are obstacles to youth participation in community evaluation research. It is difficult to involve youth when adults are unaware of this possibility, or perceive evaluation research as an activity that is for adult experts and not young citizens, or hold attitudes which frustrate youth participation, or behavior in adultist ways as a result of their views of the roles of youth in society, or themselves lack knowledge and skills to increase involvement of young people in the institutions and decisions that affect their lives (Finn \& Checkoway, 1998). It also is difficult when young people themselves accept the adultist notion of adult control over research, or do not view themselves as a group that could organize their own project, or try to take action but lack legitimacy in the larger society (Checkoway \& Richards-Schuster, 2001a, 2001b). There are many ways for young people to participate in the decisions that affect their lives, and research is not an important priority among them. Only a small fraction of the youth population are aware of research as form of participation, and fewer still have the resources to take action of this type.

Despite the obstacles, there are opportunities for youth participation in community evaluation research, and this work has great potential for future development. Foundations and 
universities are among the institutions that have shown support for youth participation. Several foundations have increased their funding for community organizations or civic agencies which promote youth participation, and universities are a source of support for participatory community-based initiatives (Weiss, 1999). There are also national organizations that seek to strengthen strategies and provide assistance to local youth initiatives. For example, the Innovation Center for Community and Youth Development (www.theinnovationcenter.org) and the Forum for Youth Investment (www.forumforyouthinvestment.org) work as intermediaries to local groups by consulting with them on program planning. The Center for Community Change (www.communitychange.org) also works as an intermediary to community-based organizations which involve young people in organizational development and community change. Several other groups facilitate the exchange of information and mutual support through newsletters and publications, or emphasize education and training to develop knowledge and skills. For example, Youth in Focus (www.youthinfocus.net) has drafted a youth empowerment evaluation curriculum for training youth leaders and adult facilitators to design and facilitate youth-led evaluation and research. The Institute for Community Research (www.incommunityresearch. org) has established a National Teen Action Research Center and Summer Youth Action Research Institute to employ research methods, seek solutions to real problems by gathering information from their peers, and using the process as a tool for change (Schensul et al., 1997).

\section{CONCLUSION}

Youth participation in community evaluation research is increasing, and can be expected to increase further in the future. There are youth-led, adult-led, and intergenerational initiatives which involve young people in various roles. These initiatives have effects on the youth that participate, the organizations with which they work, and the communities of which they are part. They benefit from support networks that help formulate strategies, offer training and technical assistance, and provide resources which will contribute to program planning and future development.

There is need for more research to address unanswered questions which arise with increasing initiatives. For example, what are the major models and methods of participation? What are the short- and long-term impacts at the individual, organizational, and community levels? What are the factors which facilitate and limit effective practice? Are there evaluation research methods which are age-appropriate and culturally-sensitive and, if so, what are they? What types of knowledge and skills are needed by youth participants and adult allies? What special competencies are needed by adult researchers and evaluators, especially ones whose normal training lacks age-related content? What are some strategies for strengthening support for sustaining the field? What kinds of support will be needed from private institutions and public agencies, and what are some ideas for making this happen? These are not the only questions arising, but they are among the important ones.

At present, however, youth participation in community evaluation research remains relatively undeveloped as a field of practice and subject of study. There are increasing initiatives, but these operate in isolation from one another. There are increasing accounts, but these are few in number and the knowledge base remains limited. Nonetheless, our observation is that "evaluation research as participation" has great promise, and that many benefits will result from the increasing involvement of young people. If the present paper contributes to this development, then its purpose will be served. 


\section{ACKNOWLEDGMENTS}

An earlier version of this paper was presented at the annual meeting of American Evaluation Association, St. Louis, November 2001. This work draws upon information from Lifting New Voices, a project of the Center for Community Change in Washington, DC, with funding from the W. K. Kellogg Foundation and Ford Foundation.

\section{REFERENCES}

Alvarado-Mena, J., et al. (1999). Locked out: Exposing the suspension epidemic in the Oakland Public Schools. Oakland: Kids First Coalition.

Ansley, F., \& Gaventa, J. (1997). Researching for democracy and democratizing research. Change, 29, $46-53$.

Arnstein, S. R. (1969). A ladder of citizen participation. Journal of the American Institute of Planners, 35, 216-224.

Campbell, P., Edgar, S., \& Halsted, A. L. (1994, October). Students as evaluators: A model for program evaluation. Phi Delta Kappan, pp. 160-165.

Checkoway, B. (1998). Involving young people in neighborhood development. Children and Youth Services Review, 20,765-795.

Checkoway, B., \& Richards-Schuster, K. (1999). User's guide to participatory evaluation for Lifting New Voices. Ann Arbor: Lifting New Voices, School of Social Work, University of Michigan.

Checkoway, B., \& Richards-Schuster, K. (2001a). Second year evaluation of Lifting New Voices. Ann Arbor: Lifting New Voices, School of Social Work, University of Michigan.

Checkoway, B., \& Richards-Schuster, K. (2001b). Lifting New Voices for socially just communities. Community Youth Development, 2, 32-37.

Ferguson, A. (2000). Bad boys: Public schools in the making of black masculinity. Ann Arbor: University of Michigan Press.

Fetterman, D., Kaftarian, S., \& Wandersman, A. (Eds.). (1996). Empowerment evaluation: Knowledge and tools for self-assessment and accountability. Thousand Oaks: Sage.

Figueroa, L., et al. (2000). In between the lines: How the New York Times frames youth. New York: New York City Youth Media Watch.

Finn, J. L. (2001). Text and turbulence: Representing adolescence as pathology in the human services. Childhood, 8, 167-192.

Finn, J. L., \& Checkoway, B. (1998). Young people as competent community builders: A challenge to social work. Social Work, 43, 335-345.

Fountain, S. (1995). It's only right! A practical guide to learning about the convention on the rights of the child. New York: Education for Development Section, UNICEF.

Freudenberg, N., Roberts, L., Richie, B., \& Taylor, R. (1999). Coming up in the boogie down: The role of violence in the lives of adolescents in the South Bronx. Health Education \& Behavior, 26, 788-805.

Gaventa, J. (1993). The powerful, the powerless, and the experts. In P.Park, et al.(Eds.), Voices of change: Participatory research in the United States and Canada. Toronto: Ontario Institute for Education.

Greene, J. C. (2000). Challenges in practicing deliberative democratic evaluation. New Directions for Program Evaluation, 85, 13-26.

Greenwood, D. J., \& Levin, M. (1998). Introduction to action research: Social research for social change. Thousand Oaks: Sage.

Guidinger, K., \& Linnane, P. (1996). Youth evaluators project: A report of first year activities, September 1995-July 1996. Milwaukee: Planning Council for Health and Human Services.

Hart, R. (1997). Children's participation: The theory and practice of involving young citizens in community development and environmental care. London: Earthscan. 